\title{
PRAGMATIC MARKEDNESS AND SYNTAX
}

\author{
ARIE VERHAGEN
}

A distinction is made between two types of pragmatics: the pragmatics of concrete sentence contents on the one hand, and the pragmatics of construction types on the other. The latter type is severely underdeveloped, also in work within the generative framework; despite the theoretical recognition that grammars have only a limited domain of explanation, there is in practice a strong preference for explanations in terms of grammatical structure. It is proposed to consider the question of the relation between grammar and pragmatics as an entirely empirical one. In this spirit, the distribution of adverbial phrases in Dutch is considered, with respect to several interpretive factors that are related to word order. An explanation of the phenomena involved is offered in terms of pragmatic markedness conventions, and some general properties of such conventions are established. Finally, some conclusions are drawn with respect to the relations between conversational maxims and the markedness conventions, in terms of the difference between functional and theoretical explanations. The results confirm the general idea of human cognitive competence as consisting of several relatively autonomous and relatively simple subsystems.

\section{Background}

Since Grice's William James Lectures (in 1967) and their first partial publication (Grice 1975, 1978), the conversational maxims have become an important tool for much work in the field of pragmatics. Now, several kinds of work that are in fact

Editors' note. This paper was originally presented at the Conference on Possibilities and Limitations of Pragmatics, organized at the Centro Internazionale di Semiotica e di Linguistica, Urbino University, in July 1979, and offered to this journal shortly afterwards and turned down. The reason was not lack of inherent quality, but rather a considerable doubt on our part whether the general character of the paper and its concern with the syntax and interpretation of sentences was germane to our editorial purposes. We therefore advised the author to hawk his ideas around and depending on the feedback, decide whether or not to publish the paper in its original form.

Since the ideas contained in the paper appeared to give rise to conflicting reactions (partly depending on which side of linguistics people are on: it is hard for both syntacticians and pragmaticians to agree on what is interesting), it seemed only fair to give our readers the opportunity to see and judge for themselves. The question of relationship between structure and function of language could then, perhaps, from being an article-of-faith become a central concern of undogmatic research in different fields of linguistics (though, maybe one should warn against undue optimism in this respect). 
quite different are subsumed under the same heading of 'pragmatics'; yet I think there is a general tendency in the way the Gricean maxims are usually applied, which $I$ here want to confront with some criticism and especially with an alternative view,

In Grice (1975), Grice himself devotes most attention to implicatures and especially to cases of 'exploitation' of the conversational maxims; he does not mention implicatures which do not involve a violation of the maxims, except by way of being complete, it secms. And even apart from that, it is clear that his concern is almost entirely with the analysis and explanation of what one could call 'secondary interpretations, i.e. interpretations of utterances which are not (assumed to be) present in the literal meaning of the sentence used in the utterance. This feature is very general [1], but in my opinion also challengeable. This way of applying the maxims necessarily involves "the conventional meaning of the words used", as Grice calls it (1975: 50), together with other things, including aspects of the context of the utterance. Thus, what we have is a direct application of the maxims to complete, lexically filled up sentences. The same characterization applies to, for example, Searle's analysis of indirect speech acts (Searle 1975). Thus, the explanation of why a request can, under appropriate circumstances, be made indirectly by means of a question or an assertion, crucially involves the lexical content of the sentences concerned; for example, they have to be questions or statements about the ability of the hearer to do something (e.g., Generalization 1 in Searle 1975: 72).

This type of pragmatics, i.e. explanation of secondary interpretations by means of direct application of conversational maxims to concrete sentences, might therefore be called the pragmatics of (lexical) sentence contents. It is definitely not a pragmatics of construction types. This approach, though not necessarily wrong, is therefore, in my opinion, fundamentally limited: it offers no prospect for gaining insight in to the way the structure and the use of language are related;i.e. it seems quite unlikely that research in this type of pragmatics will lead to the formulation of general abstract principles concerning the relation between the structure and the use of the language system. It is not a logical or moral necessity that one should deplore this situation, but it is surely a serious limitation: pragmatics is severely underdeveloped in the field that seems to be the most interesting from the point of view of general interest in human cognitive competence, its different parts and their interaction, which should, in my opinion, constitute the central concern of the humanities.

The relation between the structure and the use of language is, in principle, made into a research problem in generative grammar. The assumption of the autonomy of

[1] One exception that I am aware of, is Kempson (1975), which contains an attempt to explain pragmatically the existential presuppositions generally associated with definiteness of noun phrases, in a way which does not crucially involve lexical meaning, at least not meaning of lexical formatives. 
principles of grammar, accompanied by the recognition that linguistic competence interacts with other cognitive capacities in the actual use of language, is almost necessarily complemented by the hypothesis of the autonomy of principles of performance. Thus the theory of grammar is assigned a limited domain of explanation, and is assumed to be embedded in a more general theory of 'semiotics', or something similar [2]. The background to this view is the assumption that the complexity of natural languages must be explained in terms of the interaction of different systems, each of which is essentially simple. This is true, in principle, i.e. for the theory. In the practice of generative grammar, however, it is often used only at moments when attempts for structural explanations break down, i.e. this so-called autonomous systems view is in practice often only a means to keep the syntax nice and clean (in itself perhaps a legitimate goal), but in fact there is a preference for structural explanations, sometimes tacit, sometimes not (as an example, $c f$. Koster 1978: 5). As a result, there is very little research on specific problems of linguistic description with the aim of clarifying the problem of the relation between structure and use of language, also in this branch of linguistics. Some important exceptions are Guéron $(1976,1979)$ and Erteschik-Shir (1979) but in general, explanations in terms of structure are considered to be somehow more important for our understanding of the nature of language, which is perhaps a heritage from (American) structuralism, where the only really valid linguistic explanations were those in terms of distribution.

In contrast, I would like to take the theoretical picture (as outlined above) seriously, so that the question of the boundaries between different systems and the points of interconnection is an entirely empirical one, and we do not have a priori preferences for certain types of explanation, as this will generally lead to reductionism, whether one says one wants it, or not.

The research that this paper reports on, was undertaken as a case study on the boundaries of grammar and its relation to pragmatics, also in the hope of finding general properties of pragmatic phenomena, so that there would be a line along which further research might progress. The problem selected for this case study was the distribution of adverbial phrases, in particular in Dutch. One reason for this choice was also that their distribution in Dutch, as well as in English, seems to pose problems for several parts of syntactic theory which otherwise appear to be well motivated; for the moment, it suffices to refer to the fact that a correct description of adverbial distribution in English apparently has to involve some notion of 'transportability' ( $c f$. Keyser 1968; Jackendoff 1977), which does not even fit into very unrestricted transformational frameworks, because its structural description simply cannot be formulated as a Boolean condition.

[2] This is in fact a remarkably constant factor in the work of Chomsky. $C f$., for example, Chomsky (1957: 102, and 1975: 105). 


\section{Some markedness conventions for information structure [3]}

\subsection{Adverbial phrases in Dutch}

At first sight, Dutch also seems to require some version of transportability in order to account for the distribution of adverbials (Koster 1978: 16). The underlying order of the main constituents of a Dutch sentence is as follows:

$$
\text { COMP ..... NP } \mathrm{NP}_{\text {subj }} \ldots . . . \mathrm{NP} \text { io } \ldots . . . \mathrm{NP}_{\text {do }} \ldots . . \mathrm{V}
$$

Thus, Dutch is an SOV language; the (non-prepositional) indirect object precedes the direct object. In all positions indicated by dots in (1), numbered 1-4, sentence adverbs (of the type probably, unfortunately, etc.) may occur, though position 1 , to the left of the subject, is somewhat marked and acceptability partly depends on the nature of the subject ( $c f$. Koster 1978: 15, and below, 2.4). Examples are presented in (2) ((2a) is generally considered acceptable too).
(a) ? dat helaas
de leraar
zijn auto verkocht heeft that unfortunately the teacher his car sold has dat de leraar helaas zijn auto verkocht heeft that the teacher unfortunately his car sold has

dat de leraar zijn auto helaas verkocht heeft
that the teacher his car unfortunately sold has

Predicate adverbs are even harder to get in position 1 of (1); they are completely acceptable in positions 2, 3 and 4, but not, it seems, if to the left of an S-adverb. $C f$. (3) and (4).

(3) (a) ?? dat machinaal Louise de koeien heeft gemolken that mechanically Louise the cows has milked

(b) dat Louise machinaal de koeien heeft gemolken that Louise mechanically the cows has milked

(c) dat Louise de koeien machinal heeft gemolken that Louise the cows mechanically has milked

(4) (a) dat Louise gelukkig de koeien machinaal heeft gemolken that Louise fortunately the cows mechanically has milked

(b) ?? dat Louise machinaal de koeien gelukkig heeft gemolken that Louise mechanically the cows fortunately has milked

[3] This paragraph is partly an excerpt from Verhagen (1979b) and partly an extension of that paper. It should be noted that I use pairs of question marks where other people have used stars to indicate unacceptability. The reasons are, firstly, that I often found it difficult to make such absolute judgments on cases of adverbial distribution, secondly, that there are ways of improving the sentences involved by means of (contrastive) stress, which never gives any help in clear cases of ungrammaticality, like violations of the Complex NP Constraint. On the role of intonation, see also the rest of the text. 
So it seems that we have the following generalizations concerning the distribution of adverbial phrases in Dutch (' $\mathrm{X}<\mathrm{Y}$ ' means that $\mathrm{X}$ must precede $\mathrm{Y}$, i.e. $\mathrm{Y}$ cannot be to the left of $X)$ :
(a) $\operatorname{AdvP}<\mathrm{V}$
(b) $\mathrm{COMP}<\mathrm{S}-\mathrm{adv}$
(c) $\mathrm{NP}_{\text {subj }}<$ P-adv
(d) S-adv $<$ Padv

These facts have generally been taken to imply that the grammar must distinguish different deep structure positions for $S$ - and $P$-adverbs respectively; for example, by means of the phrase structure rules in (6) and (7) [4] (cf. Koster 1978: 12; S is introduced by the rule $S^{\prime} \rightarrow$ COMP $S$ ).

(6) $\mathrm{S} \rightarrow(\mathrm{AdvP} *) \mathrm{NP}$ VP

(7) $\mathrm{VP} \rightarrow(\mathrm{AdvP} *)(\mathrm{NP}) \mathrm{V}^{\prime}$

(8) $\mathrm{V}^{\prime} \rightarrow(\mathrm{NP}) \mathrm{V}$

Thus, (9) (shown in fig. 1) represents a full-fledged base structure, given these rules. In order for the grammar to produce all grammatical strings in accordance with the generalizations in (5), one or more movement rules are needed. At first sight, two options are available: movement of adverbials to the right over a noun phrase ("Adv-postposing", cf. Booij 1974), or movement of noun phrases to the left over the adverbials ("NP-preposing", cf. De Haan 1979). The rules would have to be iterative and optional. Both would, in terms of linear strings, have the effect of interchanging the positions of an adverbial and an adjacent noun phrase, thus preserving the original order between $\mathrm{S}$ - and P-adverbs (see generalization ( $5 \mathrm{~d}$ )). However, both rules lead to violations of otherwise well motivated principles of syntactic theory.

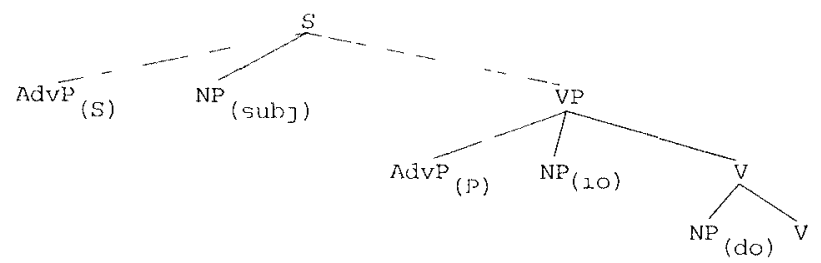

Fig. 1. (9): a full-fledged base structure.

14] The star "*" means that an arbitrary number of the phrases involved may be chosen in an application of the rule. Instead of "AdvP" one should actually read " $\mathrm{X}$ ", i.e. any maximal major category, because there is no specific syntactic category with adverbial function in Dutch, but AP's, PP's, S's and NP's all occur in this function, with the same distribution; $c f$. Verhagen (1979b: 394-5). A sentence adverbial may also occur to the right of a sentence, under some specific conditions. This must be regarded as a case of right-dislocation; it is discussed in Verhagen (1979d). 
As for Adv-postposing, note that several applications of such a rule would involve lowering of the adverb involved: an S-adverb to the right of the direct object would be lower in the tree than its original position. This is in conflict with the general c-command condition on movement, generally assumed and motivated in generative syntax ( $c$. Koster 1978, Chomsky 1979).

The NP-preposing alternative would not violate the c-command condition. However it would produce derived structures in which originally 'lower' NP's have been promoted to higher positions, e.g. immediately dominated by $S$, structurally in the same position as the subject. Now, there are several conditions on transformations that crucially involve a structural difference between the positions of the NP's in a sentence; for example, the Superiority Condition of Chomsky (1973) states that if a rule applies ambiguously to a certain structure, it must in fact apply in such a way that only the structurally superior position (roughly, the one that is highest in the tree) is affected. For example, if a sentence has wh-phrases in both the subject and the direct object position, only the subject can be fronted, because it is structurally superior to the direct object. In combination with an NP-preposing rule as suggested above, it is then predicted that, inter alia, direct objects would become available for rules from outside $S$, namely after preposing, i.e. if to the left of an S-adverb. This is never the case, however. Furthermore, such a rule would be a strong violation of Emonds' (1976) Structure Preserving Hypothesis, which is motivated most strongly preciscly for NP-movements. Moreover, both postposing and preposing would have to be sensitive to more than just categorial information, namely also to functional information, as an adverbial to the right of a predicate nominal NP is impossible.

The usual response to this situation is either the introduction of ad hoc descriptive devices, whose formal properties are quite unclear (transportability, scrambling, and the like), or, most commonly, the problem is disregarded. In my opinion, the source of the problems is the tacit assumption in all this that the ordering restrictions on adverbial phrases reflect their syntactic properties, so that there must be a syntactic explanation ( $c f$. the remarks in 1 , on the preference for structural explanations in generative grammar). I will now argue that this is in fact incorrect and outline the features of a better analysis. First, I will give the basic assumption involved, and in subsequent separate paragraphs, the most important consequences. In the course of the discussion, it will also become clear that structural analyses as described above have disregarded some crucial phenomena and probably are even incapable in principle of expressing the correct generalizations.

It has, to my knowledge, not been stated explicitly in the literature before that there are subtle differences of interpretation between the sentences in (2). These differences can best be illustrated by giving the possible paraphrases of (2b) and (2c); these are given in (10) and (11) respectively.

(10) (a) what the teacher sold, unfortunately, was his car

(b) what the teacher did, unfortunately, was to sell his car 
(11) what the teacher did with his car, unfortunately, was to sell it

In $(10)$, the paraphrases of $(2 \mathrm{~b})$ are given that are possible when (non-contrastive) sentence stress is on the direct object ("his car"). Sentence (2c) has stress on the main verb ("sold"), and (11) is its only possible paraphrase of this form. The paraphrases reflect the partitioning of the sentences concerned into focus and presupposition. Thus, it appears that sentence adverbs in Dutch undergo "association with focus" ( $c f$. Jackendoff 1972: ch. 6.5); I therefore rename them "focal modifiers" (briefly: f-modifiers). In (2b), the presupposition is either that the teacher sold something, which is asserted to be his car, or that the teacher did something, which is asserted to be "to sell his car" (focus). In (2c), it is presupposed that the teacher did something with his car, which is asserted to be "to sell it". So in (2c), where the phrase "his car" is to the left of the adverbial, it cannot be part of the focus. Thus we have the following constraint on association with focus of f-modifiers [5]:

(12) The focus must be to the right of the focal modifier: f-modifier < focus

It is not required that the focus be immediately to the right of the f-modificr. The reason is that sentence $(2 \mathrm{~b})$ can also have the interpretation (11), provided that sentence stress is on the main verb (as it is in (2c)). In that case, the direct object ("his car"), which is immediately to the right of the f-modifier, is presuppositional. However, though this interpretation seems to be possible, it is certainly not natural; this is a problem to which I will return.

The simple constraint in (12) gives rise to a number of interesting predictions, once we consider the way it interacts with some straightforward conventions on the use of certain types of phrases and ordering strategies [6].

[5] Perhaps this constraint must in fact be taken as a liniting factor on the choice of focus itself; $c f$. Verhagen (1979a). In fact, I believe it follows from other principles, in particular (28) and the functionality principle, both discussed in 2.4 .

[6] A very interesting consequence, not treated in the rest of this paper, is related to Guéron's $(1976,1979)$ condition on Extraposition from NP, to the effect that this is only possible from NP's in focus. She illustrates this condition for English, especially with respect to the difference in Extraposition-possibilities between subjects and objects, where she shows that a purely structural analysis will inevitably meet great problems. Guéron's condition implies for Dutch, given constraint (12), that Extraposition is not possible from NP's to the left of an f-modifier; this is borne out:

(a) Piet heeft gelukkig de auto gekocht die ik 't mooist vond Peter has fortunately the car bought which I most beautiful found

(b) ?? Piet heeft de auto gelukkig gekocht die ik 't mooist vond Peter has the car fortunately bought which I most beautiful found

Sec Verhagen (1979b) for further discussion. 


\subsection{Indefinites}

It is a well known fact that if one wants to introduce a new entity into a discourse, the preferred way of doing so is by using an indefinite noun phrase: in the unmarked case, indefinites are used to present new information, thus belong to the focus. We may therefore formulate the following convention:

unmarked: indefinite $N P$ in focus

The consequence of (13) and (12) taken together is that indefinite NP's are to the right of $\mathrm{f}$-modifiers in the unmarked case. This could explain the fact that $\mathrm{f}$-modifiers generally may occur both to the left and to the right of definite NP's (see the examples in (2)), but that problems arise with respect to indefinites [7]:

(14) (a) Jan heeft waarschijnlijk een auto verkocht John has probably a car sold

(b) ?? Jan heeft een auto waarschijnlijk verkocht John has a car probably sold

There are two classes of exceptions to the patterns of (14); they are exemplified in (15) and (16), which have an indefinite NP to the left of an f-modifier.

(15) $\mathrm{Zij}$ heeft een vriend van me vermoedelijk de bons gegeven She has a friend of mine presumably the sack given

(16) Jan zal een auto waarschijnlijk weigeren John will a car probably turn down

Both (15) and (16) are acceptable. But in (15), the indefinite NP "a friend of mine" must be interpreted as specific; a non-specific interpretation is impossible, which is not the case if the adverb is to the left of this NP. In (16), the NP "a car" must be interpreted as generic ("any car"). The explanation of (15) is straightforward: the NP must be presuppositional by (12), therefore it cannot be taken as introducing a new entity; it contains the indexical expression "of mine", so it is easily taken as referring to a particular person (thus, "specific"). In (16), the indefinite NP must equally be presuppositional, but it does not contain an indexical expression, so it is hard to take it as referring to a particular; in the context of "turn down", however, it is naturally taken as referring to a kind, i.e. to the class of cars, the definition of which is the meaning of the noun car, something which is always known (therefore possible as part of the presupposition).

[7] As for the form of the examples: in root sentences in Dutch, the main verbs stay in the original position ( $c f$. (1) above), but the tensed verb occurs in second position, no matter what is in first position. 
What we have then is that indefinite NP's to the left of focal modifiers cannot be interpreted in an unmarked way, i.e. not as non-specific. Acceptability then depends on special conditions with respect to the possibility and degree of naturalness of a specific or generic interpretation; if these interpretations are not available in a given context (as in (14b)), the sentence is unacceptable.

The consequence for the theory of this analysis is that there is no need for the grammar to derive different semantic representations, or "logical forms", for the sentences with, for example, indefinites as non-specific of to the right of an f-modifier and the same indefinites as generic if to the left of an f-modifier; there is also no need then to assign such sentences essentially different syntactic structures to serve as input to the rules of semantic interpretation. In particular, these phenomena do not provide any motivation for assuming the existence of the non-structure-preserving rule of NP-preposing, mentioned in 2.0.

\subsection{Pragmatic unequivocality}

As a consequence of (12), anything to the left of an f-modifier in a sentence unambiguously belongs to the presupposition. Therefore the position of an f-modifier is relevant to the hearer to reconstruct the information structure as intended by the speaker. It seems natural to suppose that an f-modifier is expected to occur in a position that supplies the most information, which is the position in which the presuppositional elements are to the left of the f-modifer, as far as possible. Thus it is unmarked that the focus immediately follows the focal modifier, as stated in (17).

$$
\text { unmarked: [ ...f-modifier-focus ... ] }
$$

What we have here is a pragmatic markedness convention, which can be regarded as a case of the interaction of (12) with general pragmatic principles; for instance, one might say that (17) embodies a specific case of the first maxim of quantity, the maxim of relation and several maxims of manner (especially the second one, "avoid ambiguity") [8].

Recall now that sentence ( $2 b)$ could in principle be paraphrased as in (11), i.e. it could have the same interpretation as $(2 \mathrm{c}$ ) (provided that stress was on the main verb), but that this interpretation was unnatural for $(2 b)$. This problem is immediately explained by convention. (17): in the interpretation (11) of (2b), there is something presuppositional between the focal modifier and the focus, which 'violates' (17).

In the same vein, it is correctly predicted that the non-specific interpretation of indefinites immediately to the right of an $\mathrm{f}$-modifier is preferred: in case of an inter-

[8] There appears to be quite some redundancy among the maxims, partly noted by Grice himself (Grice 1975: 46). I leave that aside, however. 
pretation as specific or generic they would have to be taken as presuppositional, which would in this case cause another 'violation' of (17).

\subsection{Pronominals}

In 2.1 , I formulated the convention that it is unmarked for indefinite NP's to be in focus as in (13). Another way to put the same thing is as follows:

(18) $\mathrm{u}$ focal $=+$ focal $/[$-definite $]$

This is to be read as, literally, "the unmarked value of 'focal' is + for indefinites", in simple terms: indefinites belong to the focus in the unmarked case. In this way, the convention has the canonical form of a markedness convention (MC) according to Kean (1975), which is as in (19):

(19) $u F \rightarrow \alpha F / X$

This states that the unmarked value of a feature $F$ is $\alpha$ ( $\alpha$ ranging over + and - ) in the context $X$.

One of the central elements in Kean's theory of markedness is the "Complement Convention", according to which every markedness convention of the form (19) has a set of rules associated with it, which together exhaustively characterize the marked and unmarked specifications of the feature involved (i.e. the one to the left of the arrow). The Complement Convention reads as follows (cf. Kean 1975: 22), with (19) repeated as $(20 \mathrm{a})$ here:

(20) (a) u F $\rightarrow \alpha \mathrm{F} / \mathrm{X}$

(b) $\mathrm{m} \mathrm{F} \rightarrow-\alpha \mathrm{F} / \mathrm{X}$

(c) $\mathrm{u} F \rightarrow-\alpha \mathrm{F} / \mathrm{X}$

(d) $\mathrm{mF} \rightarrow \alpha \mathrm{F} / \overline{\mathrm{X}}$

The symbol $r n$ stands for "marked", $\overline{\mathrm{X}}$ for the complement set of X ("all elements - from the domain involved - that do not belong to the set defined by X"). An example of a markedness convention in phonology (the framework of Kean 1975) is (21).

(21) $[$ u son $] \rightarrow[-$ son $] /[+$ cons $]$

This states that it is unmarked for consonants to be non-sonorant. Application of the Complement Convention yields:

(22) (a) [u son] $\rightarrow[-$ son $] /[+$ cons $]$

(b) $[\mathrm{m}$ son $] \rightarrow[+$ son $] /[+$ cons $]$

(c) $[u$ son $] \rightarrow[+$ son $] /[-$ cons $]$

(d) $[\mathrm{m}$ son $] \rightarrow[-\mathrm{son}] /[-\mathrm{cons}]$

The latter three rules mean, respectively, that it is marked for consonants to be 
sonorant, unmarked for non-consonants to be sonorant, and marked for non-consonants to be non-sonorant.

Note that the Complement Convention does not express a logical necessity; i.e. it is logically conceivable for there to be a rule alongside (21) to the effect that, under certain conditions, some particular non-consonants could also be unmarked non-sonorants, but this is impossible under the Complement Convention. Thus we might say that this Convention 'maximizes' the effect of a markedness convention: once you know one markedness specification for a feature, you know all of them.

In phonology, the Complement Convention is well motivated, and it seems natural to suppose that it is in fact an integral part of the notion of markedness in linguistics; thus Van Riemsdijk (1979) has argued that the Convention also applies in the domain of syntax. So it is natural to ask how it relates to (18), given that this has the appropriate form.

Now it is clear that the Complement Convention cannot be applied directly to (18): it would be predicted that definite NP's would belong to the presupposition in the unmarked case and therefore preferably occur to the left of an f-modifier, which is clearly not the case (cf. (2)); rather, definite NP's seem to be indifferent with respect to a preference for focus or presupposition. However, the Complement Convention as formulated by Kean applies to systems of binary features, in which the complement set for some feature is identical to its opposite. I based (13) on the fact that it is an unmarked use of indefinites to introduce new entities into a discourse. And with respect to this feature, noun phrases do not divide into two complementary sets, but into several groups, such that at one end of the scale are, as noted, the indefinites, and at the other end pronominal NP's. Personal pronouns are typically used for entities which are known to such a degree that the speaker does not even need a (definite) description to refer to them. Thus, it is unmarked for pronouns not to belong to the focus:

\section{unmarked: pronominal NP not in focus}

Just like (13), (23) can be formulated in the canonical form of MC's:

(24) $\mathrm{u}$ focal $=-$ focal $/[+$ pronominal $]$

Together with the convention (17) (the unmarked order in information structure is the one where the f-modifier introduces the focus), it is predicted that pronouns

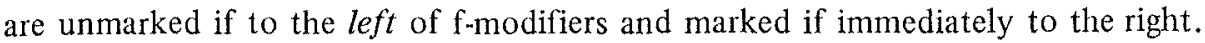
This can account for the difference between the sentences in $(25)$, which pattern in precisely the opposite way to (14).

(25) (a) ?? Jan heeft waarschijnlijk hemgezien

John has probably him seen

(b) Jan heeft hem waarschijnlijk gezien

John has him probably seen 
Now it is possible for a speaker to indicate explicitly that a pronoun is in focus, namely by 'giving it sentence stress. In that case, it is acceptable if to the right of an f-modifier, in accordance with (17): in (26), the focus is immediately to the right of the f-modifier:

(26) Jan heeft waarschijnlijk HEM gezien

John has probably HIM seen

One might wonder why (26) is only contrastive (because of 'violation' of $(23) /(24)$ ), but acceptable, while ( $25 \mathrm{a})$ is rather unacceptable, though it also 'violates' only one $\mathrm{MC}$, in that case (17). I think the explanation lies in some 'functionality principle' to the effect that sentences with marked information structures are only acceptable if they are somehow functional. We can say that in (25) there is no reason at all to create a marked information structure with the f-modifier not introducing the focus, while in (26) there may be a very good reason to use a pronominal NP, for example, if the speaker does not know anything more about the referent than that he is present. Indeed, (26) is preferably understood as if it were accompanied by some pointing gesture; the pronoun is taken as an independently referring expression rather than as an anaphoric one [9]. So the marked information structure in (26) is imaginably functional, the one in (25a) is not.

When we summarize the MC's for indefinites and pronouns (cf. (18) and (24)), we have the following picture:
(a) $\mathrm{u}$ focal $=+$ focal $/[-$ definite $]$
(b) $\mathrm{m}$ focal $=-$ focal $/[-$ definite $]$
(c) $u$ focal $=-$ focal $/[+$ pronominal $]$
(d) $m$ focal $=+$ focal $/[+$ pronominal $]$

It is clear then that these MC's together indeed show the same pattern of formal relations as is established by the Complement Convention (cf. (22)), with the proviso that the "opposite" of indefiniteness, rather than its complement, has to be taken as the content of " $\overline{\mathrm{X}}$ " in this case, which is probably caused by the nonbinary character of the system involved. Despite this proviso, the pattern in (27) clearly indicates that markedness conventions in their canonical form should play an important role in the analysis of pragmatic markedness. Even clearer indications will be treated in 2.6 and 2.7 . The consequence of all this for the theory of grammar is, again, not only that there is no need for special conditions (for pronominals,

[9] This might be the source of the difference between the following two sentences, where the subscripts indicate coreference.

(c) John $n_{i}$ was betrayed by the woman he ${ }_{i}$ LOVED.

(d) * John $n_{\mathrm{i}}$ was betrayed by the woman $\mathrm{IIE}_{\mathrm{i}}$ loved

The purported explanation of comparable data in Chomsky (1976) does not, it seems, work for cases like these, where it is the pronominal NP itself that bears sentence stress. 
indefinites, or whatever) on movement rules involving adverbials, but also that the restrictions involved need not and cannot be accounted for by the grammar at all.

\subsection{S-initial focal modifiers}

As pointed out in, inter alia, Blom and Daalder (1977), it is a perceptual strategy to expect old information (presuppositional elements) to precede new information (the focus) [10]. Thus, it is unmarked for the focus to be final in a sentence. In view of earlier MC's, the following formulation suggests itself:

(28) unmarked: [ ... focus]

For the general case of sentences containing presuppositional elements, (29) follows immediately from the combination of (28) and (17) (repeated here for convenience).

(17) unmarked: [ ...f-modifier - focus ... ]

(29) unmarked: [presupposition - f-modifier-focus]

This accounts for the fact, noted in passing by several authors (e.g. Booij 1974: 644, note 8; Koster 1978: 15), that $S$-initial position is somewhat restricted, even for S-adverbs. Thus we have the following contrast:

(30) (a) ?? dat waarschijnlijk Jan Piet zag that probably John Peter saw

(b) dat Jan waarschijnlijk Piet zag that John probably Peter saw

Booij (1974) gives the following example:

(31) ?? dat waarschijnlijk Jan zijn broer sloeg that probably John his brother hit

The relative unacceptability of (30a) and (31) cannot, of course, be attributed to the fact that the f-modifier is immediately followed by a proper name, because the same would apply to (30b), but this sentence is good. However, it is clear that (30b) can easily satisfy (29), but (30a) and (31) cannot because there is nothing to the left of the f-modifier that could be presuppositional. Non-contrastive stress being final ( $c f .2 .6$ below), we would have a situation analogous to the one involving pronominals, where the f-modifier does not introduce the focus, which 'violates' (17). But again there is a way to cancel this violation, namely making the subject focus by giving it sentence stress, thus:

[10] Of course, this was by no means discovered by Blom and Daalder. However, they do, to my knowledge, formulate this principle for the first time in such a way that interesting predictions can be derived from it. See also 2.6 below. 
(32) dat waarschijnlijk JAN zijn broer sloeg that probably JOHN his brother hit

This sentence is acceptable, though contrastive because the focus is not in final position (cf. (28)): the focus immediately follows the focal modifier, so that (17) is satisfied. That (32) is acceptable and (31) relatively unacceptable, though both "violate' just one $\mathrm{MC}$, can be accounted for by the functionality principle discussed in 2.3 in connection with (26); in (31) there is no reason to create a marked information structure; the adverb can freely be positioned towards the right, which would give a completely unmarked case; but a subject NP is not free, for grammatical reasons, to move towards the end of the sentence (the unmarked position of focus by (28)), so that if the speaker wants to have the subject in focus, he is more or less forced to make stress initial; thus the marked information structure of (32) can be called functional, in contrast to the one in (31).

Now there need not always be presuppositional elements in a sentence, i.e. we can also have situations where the focus exhausts the sentence. In that case, it is not (29) which follows from (17) and (28), but (33),

\section{(33) unmarked: [f-modifier - focus]}

Following Blom and Daalder (1977), I assume that a sentence can only be taken as focus in its entirety, if it has, in their terminology, "self-evident and immediately relevant implications", i.e. if it is an information unit whose relation to the context and the situation (the "Pragmatic Universe of Discourse" of Kempson 1975) is immediately clear from its content [11]. One type of sentence for which this condition can be easily satisfied (see also 2.6 ) is the kind which simply states something about the world as a whole, not about some specific entity in the world, i.e. sentences that have quantifying expressions (like no-one, some-one, everyone) as subjects, not referring expressions. This is the explanation of the fact, noted by Booij and by Koster, that the acceptability of sentences with S-initial S-adverbs 'depends on the nature of the subject'. Thus (34) and (35) are completely acceptable, as well as noncontrastive, in contrast to (30a), (31) and (32).

(34) dat helaas niemand zijn auto wil verkopen

that unfortunately no-one his car wants to sell

(35) dat waarschijnlijk iedereen zijn broer sloeg

that probably everyone his brother hit

The explanation is that such sentences can naturally be taken as completely focus, which gives an information structure satisfying (33), thus both (17) and (28).

[11] For discussion of these points and related ones, see Verhagen (1979c). 


\subsection{Predicate adverbials}

Adverbial modifiers are generally not necessary in a sentence for grammatical reasons. So if they are present, the speaker apparently needs them as relevant for the information he wants to convey. Thus we can say that in connection with general pragmatic principles (say, the second maxim of quantity, the maxim of relation, etcetera, $c f$. note 8 ), adverbials will belong to the focus, if they do not play some particular role in information structure (in particular, as $\mathrm{f}$-modifiers). So we can formulate (36) [12].

(36) unmarked: predicate adverbial in focus

The consequence of (36) and the constraint on focus-association (12) is that P-adverbials are to the right of S-adverbials (= f-modifiers) in the unmarked case. Now recall that I mentioned at the beginning, inter alia, that the following generalization seemed to hold:

(d) $\mathrm{S}-\mathrm{adv}<\mathrm{P}$-adv

As noted there, this has generally been taken to imply a difference in structural positions for both types of adverbials. It seems now, however, that a pragmatic analysis can at least partly account for (5d). If (36) is what is really behind (5d), then we expect to be able to find marked cases where, under special circumstances, a P-adverbial need not be in focus and thus may occur to the left of an f-modifier. Indeed, there is one way in which a constituent can be particularly relevant for the information to be conveyed without belonging to the focus, namely if it mentions a distinguishing, thus essential feature of the situation that the assertion is about, i.e. if the phrase involved functions as a topic in information structure. As proposed by Salverda (1979), the topic bears initial stress in Dutch [13]. In the specific function of topic, with this intonational feature, we do indeed find P-adverbials to the left of focal modifiers:

[12] It is a legitimate question whether (36) could also be given in the canonical form of an $\mathrm{MC}$; it would have to be something like the following:

(e) $\mathrm{u}$ focal $=+$ focal $/$ P-adverbial

It is not clear, however, how the Complement Convention would have to apply to (e); what is the complement or opposite set of "P-adverbial"? But perhaps the formulation we should consider is (f) rather than (e):

(f) $\mathrm{u}$ focal $=+$ focal $/$ not structurally required elements

It is still not clear what the complement set (namely: structurally required elements) would actually contain: subjects? clitics, as mere manifestations of the subcategorization of the verb? So for the time being I confine myself to the formulation in (36).

[13] Sentence stress, which marks the focus, is defined as the final change of pitch in $S$ in an intonational contour ( $c f$. Blom and Daalder 1977). 


dat je machinaal helaas geen bomen kunt kweken
that you mechanically unfortunately no trees can grow

(38) dat men met pijl en boog waarschijnlijk op konijnen joeg that one with arrow and bow probably (at) rabbits hunted

Given the functionality principle discussed before, we can calculate the following two situations in which a P-adverbial might even occur in S-initial position, according to this analysis: (a) the P-adverbial is topic, the subject is focus; (b) the P-adverbial is topic, the rest of the sentence is focus. Examples are given in (39) and (40) respectively [14].

(39) dat machinaal zelfs Jan een koe kan melken that mechanically even John a cow can milk

(40) dat met de Mercedes niemand op vakantie wil gaan that with the Mercedes no-one on holiday wants to go

So generalization (5c) is accounted for by (36) too, precisely as far as it holds. The consequences for the grammar are rather drastic. We have already seen that there is no need for special restrictions on movement involving adverbials, in connection with definiteness and so on. We now see that there is no need for the grammar to make syntactic-structural differences between different types of adverbials, and even that it would be wrong to do so, because certain grammatical sentences could then not be derived. The partial ordering restrictions that exist can all be accounted for in a theory of pragmatic markedness; this enables us to have the syntax generate any adverbial phrase in any structural position. Assuming that $S=V^{3}$ in $X$-bar theory ( $c f$. Jackendoff 1977), the following rule schema will give us the structural 'backbone' of the vast majority of Dutch sentences ( $c f$. Verhagen 1979b).

(41) Generalized Major Base Rule: $\mathrm{V}^{\mathrm{i}} \rightarrow \mathrm{X}^{3 *} \quad \mathrm{~N}^{3} \quad \mathrm{X}^{3 *} \quad \mathrm{~V}^{\mathrm{i}-1}$

where $\mathrm{X}^{3^{*}}$ is an arbitrary number of categories of any major type (NP, AP, PP, or $\mathrm{S}$ ), specifying a non-argument position, i.e. adverbial or predicate nominal, and $\mathrm{N}^{3}$ is NP, specifying an argument position, i.e. subject, indirect object and direct object at $V^{3}, V^{2}$ and $V^{1}$ respectively.

Because there appears to be no real need for movement rules involving adverbials, the problems for syntactic theory which such rules would inevitably give rise to, as described in 2.0 , disappear completely, of course.

[14] In all the cases in (37)-(40), the predicate adverbial with topical function seems to function as a 'domain adverb' in the sense of Bellert (1977); they define a 'domain of interpretation', in which the rest of the assertion is valid (according to the speaker): in (37), it is asserted of a situation characterized as "mechanical", that one unfortunately cannot grow trees in that way, i.e. the assertion that one cannot grow trees is (unfortunately) valid in a domain of interpretation defined as "mechanical". See Verhagen (1979b: 391-2) for discussion and extension to other types of adverbial modifiers. 


\subsection{Contrastive stress [15]}

The analysis presented here originates in the study of problems of adverbial distribution and interpretation. But some of the conventions proposed have effects beyond these problems. Thus, it follows from $(23) /(24)$ in 2.3 , to the effect that pronouns are presuppositional in the unmarked case, that it is marked for them to bear sentence stress, as they will then have to be taken as being in focus. That this is correct was already seen from (26), which is a case of so-called contrastive stress. So one case of contrastive stress can be traced back to a marked information structure. In Blom and Daalder (1977), the possibility is considered that all cases of contrastive stress can be analysed as in fact cases of pragmatically marked information structures. Consider convention (28) from 2.4 again.

(28) unmarked: [ ... focus]

This explains why final stress is generally non-contrastive and initial stress often contrastive. Furthermore, it leaves open the possibility that initial stress need not always be contrastive, namely in the case of sentences which are focus in their entirety. Blom and Daalder give examples of sentences with non-contrastive initial stress of the following kind:

de JUF is ziek
the TEACHER (fem.) is ill

(43) je KOFFIE wordt koud your COFFEE becomes cold

These can indeed be considered as sentences with immediately relevant implications, i.e. the way they are supposed to relate to some situation, their 'point', is immediately clear for practically all Dutch speakers, as they reflect standard situations. Thus it is natural to take them as completely focus, and their information structure is not marked by (28), because there even are no presuppositional elements that could follow the focus, which explains why initial stress is not contrastive in these cases. It is contrastive in a case like (44), which is structurally and intonationally completely parallel to (42) and (43), but not easily taken as not containing presuppositional elements, because it does not reflect some standard situation.

(44) zijn FOUT is begrijpelijk

his ERROR is understandable

Therefore (44) is taken as a case of an S-initial focus followed by presuppositional elements, which is marked by (28).

[15] The point in this section is elaborated and compared with different analyses in Verhagen $(1979 \mathrm{c})$. 
What is still not explained, however, is why final stress generally makes it impossible to take the entire sentence as focus; we saw in 2.4 that this was only possible for sentences with quantifying expressions in subject position, not for sentences with referring expressions as subjects. Blom and Daalder therefore say that they have not completely succeeded in giving a pragmatic account of contrastive and non-contrastive stress. Note, however, that it is not possible to deduce any prediction about the unmarked positions of stress directly from (28). With respect to stress, consequences only follow from (28) if we know whether some sentence contains presuppositional elements or not; i.e. given that focus is determined by sentence stress, it follows from (28) ('as a theorem', so to speak) that the unmarked position of stress is final if the sentence contains presuppositional elements; thus:

$\mathrm{u}$-position stress $=$ final $/ \mathrm{S}$ contains presupposition

This has the canonical form of an MC (cf. (19)), so we can see what application of the Complement Convention would yield. The results are as follows:

(46) (a) $\mathrm{u}$-position stress $=$ final $/ \mathrm{S}$ contains presupposition

(b) m-position stress $=$ non-final $/ \mathrm{S}$ contains presupposition

(c) u-position stress $=$ non-final $/ \mathrm{S}$ does not contain presupposition

(d) m-position stress $=$ final $/ \mathrm{S}$ does not contain presupposition

(46b) and (46c) represent, respectively, the cases of contrastive initial stress (like (44)), and those of non-contrastive initial stress (like (42) and (43)). And (46d) is precisely the statement that we needed to complete the analysis: it says that it is marked for final stress to be associated with sentences that are focus in their entirety. This is due to the nature of the Complement Convention as maximizing the effect of a markedness convention (cf. 2.3 and 3 below): under the analysis of Blom and Daalder initial stress is only one unmarked case for completely-focussentences, the Complement Convention turns it into the unmarked case.

\subsection{The scope of predicate adverbials}

In 2.5, I established the convention that it is unmarked for predicate adverbials to be in focus. Taken in conjunction with the functionality principle, this means that when one encounters a predicate adverbial in a sentence, one should take it as belonging to the focus unless there is clear evidence to the contrary. In 2.4 , I formulated the well known principle that the focus is final in the sentence in the unmarked case. It follows then that in the unmarked case, no presuppositional elements will follow a predicate adverbial. That is, from conventions (28) and (36) convention (47) follows, 'as a theorem' again.

(28) unmarked: [ ... focus]

(36) unmarked: predicate adverbial in focus

(47) unmarked: elements to the right of predicate adverbial in focus 
We can already predict from (47) that unstressed personal pronouns, for example, will be bad if to the right of a predicate adverbial; i.e. this analysis necessarily implies that predicate adverbials will also show some scope-phenomena. This is correct; for example, see (48).

(48) (a) ?? Louise heeft mondeling hem geëxamineerd Louise has orally him examined

(b) Louise heeft hem mondeling geëxamineerd Louise has him orally examined

(c) Louise heeft mondeling HEM geëxamineerd Louise has orally HIM examined

But with the Complement Convention, an even more specific prediction is made; (47) can also be formulated as in (49a), and the Complement Convention yields the whole of (49):

(49) (a) $\mathrm{u}$ focal $=+$ focal / elements to the right of P-adv

(b) $\mathrm{m}$ focal $=-$ focal / elements to the right of P-adv

(c) $\mathrm{u}$ focal $=-$ focal / elements to the left of P-adv

(d) $\mathrm{m}$ focal $=+$ focal / elements to the left of P-adv

Cases (c) and (d) state that not only it is unmarked for elements to the right to be in focus, but also for alements to the left to be presuppositional. Given the grammatical freedom of distribution of adverbials and the functionality principle, the analysis thus implies the following: All adverbials mark the boundary between presupposition and focus in a sentence, either as f-modifier (see (29)), or as the first clement of the focus in all other cases [16]. Most importantly, the analysis predicts that indefinite NP's will show exactly the same differences of interpretation depending on the order with respect to predicate adverbials, as with sentence adverbials ( $\mathrm{f}$-modifiers). This is borne out:

(50) (a) de voorzitter bracht schriftelijk een onheilstijding over the chairman conveyed in writing a message of evil

(b) de voorzitter bracht een onheilstijding schriftelijk over the chairman conveyed a message of evil in writing

Sentence (a) must be interpreted as stating that the chairman conveyed some message of evil in writing; but sentence (b) means that the chairman generally conveyed messages of evil in writing, i.e. non-specific if to the right, generic if to the left.

As I said, this is all implied by the analysis as given in the preceding paragraphs,

[16] It should be emphasized that nothing of this kind follows for the marked use of predicate adverbials as topic (see 2.5 ), of course. 
and therefore it gives striking confirmation, I think. It is also worthwhile to note that existing structural analyses as referred to in paragraph 2.0 , are completely incapable of handling these cases, because they try to relate phenomena such as discussed in 2.1 to the allegedly unique structural position of sentence adverbials (immediate domination by $\mathrm{S}, c f .2 .0)$. In view of cases like (50) one would have to conclude that there is in fact no structural difference between $S$ - and P-adverbials; but then the structural explanation for the generalizations $(5 c)$ and $(5 d)$, concerning the distribution of predicate adverbials, would be lost, inter alia, and the addition of an analysis like the one in 2.5 is necessary, making the description highly redundant, I suspect.

\section{The Complement Convention and the role of the maxims}

In the preceding paragraphs we have found at least two strong cases for claiming that the Complement Convention is indeed operative in the field of pragmatics, as it is in phonology and possibly in syntax (Van Riemsdijk 1979), so that the hypothesis suggests itself that this Convention is an integral part of the notion of markedness, independent from some particular component of linguistic theory. Consequently, and in view of the fact that (45) and (47) are not axioms, one might speculate whether markedness is a primitive notion of linguistic theory, of rather the result of the interaction of grammatical and one or more other cognitive capacities. As an indication of what $I$ have in mind, consider the relation between the Complement Convention and the Gricean maxim of manner ("Be perspicuous" and especially "Avoid ambiguity"). In 2.7, it was shown that the analysis entailed the convention that in the unmarked case, everything that follows a predicate adverbial is part of the focus. I might have continued then, like I did in 2.2, with concluding that the position of a P-adverbial is relevant to the hearer to reconstruct the intended information structure: he may assume, unless there are clear indications to the contrary, that at least everything that follows it, is focal. Here too then, it is clear that the most 'perspicuous' order of elements in information structure is the one where nothing focal precedes the predicate adverbial. But this is precisely what application of the Complement Convention gave us.

Does this mean that, for example, the maxim of manner 'explains' the Complement Convention? In some sense, yes: it does not seem wrong to say that the Complement Convention facilitates reduction of ambiguity, and that this could somehow be the reason for its existence. Nevertheless, I see no way of deducing the Convention from the maxim: it does not follow at all from "Be perspicuous" that the language should employ such a system of minimal oppositions for this goal, in different areas. That is, the maxim definitely cannot explain the Convention theoret $i$ cally.

By way of conclusion then, I would like to review in general the role of the Gricean conversational maxims with respect to a theory of pragmatics, as it is, in its 
outlines, emerging from this study. First of all, note that the maxim of Quality does not seem to play any role in explaining pragmatic markedness conventions; probably this is due to the fact that it does not seem to be related in any way to the form of utterances, while the other maxims can be related to such formal aspects. As for the status of the MC's, then, they seem to form an autonomous system, in the sense that they have properties which cannot be systematically deduced from other, more primitive notions in different fields: there is no necessity that they relate to each other in a way that is predicted by the Complement Convention. Yet it is clear that at least certain aspects of the MC's can, in some sense, be naturally explained in terms of notions that are crucial to the traditional conversational maxims; in the preceding discussion they were used more than once to indicate the naturalness and the pragmatic nature of several MC's I proposed.

An analogy suggests itself with the relation between phonetics and phonology, and between substance and form, as discussed more than once in the history of linguistics. Phonological rules and their specific properties cannot be deduced from phonetic statements; yet several of them have 'functional explanations' (not identical to scientific, theoretical explanations) in terms of properties of the vocal tract. Likewise it has been suggested that some parts of the theory of syntax have functional explanations, for example in terms of certain pragmatic principles (e.g. Erteschik-Shir 1979 and references cited there). In the same vein, then, several elementary parts of a theory of the use of sentences (essentially involving information structure) can be said to have functional explanations in terms of general principles guiding purposive human behavior. That is, we say it is natural that principles of language use are not completely unlike other principles concerning the use of human capacities, without committing ourselves to the statement that the former principles, with all their specific properties, can be deduced from the latter; in other words: it is not possible to give a full theoretical account of the systematic properties of information structure just in terms of conversational maxims.

Summing up the results of this discussion, we get roughly the following picture. Gricean conversational maxims, involving principles of behavior not limited to the use of language, do enter into explanations of the relation between the syntactic form of utterances and their pragmatic appropriateness; thus they do form a part of the pragmatics of construction types. But even in pragmatics, they play a limited role, i.e. they do not exhaust the theory of the use of language. They enter into functional explanations, and they do not enter (at least it is not clear that they do) into the functional explanation of all MC's: they only partially explain some general properties of the MC's, while the other ones are still not unnatural.

I find this idea appealing, because it is essentially in accordance with the idea that properties of 'substance' are somehow reflected in 'form', but reducing one to the other is not possible: each of the partial systems that together make up cognitive capacity, is 'relatively autonomous'. 


\section{References}

Bellert, I 1977 On semantic and distributional properties of sentential adverbs Linguistic Inquiry $8 \quad 337-351$

Blom, A and S Daalder 1977 Syntaktısche theorie en taalbeschrijving Muiderberg Coutunho

Booly, G L 1974 Zinsbepalingen in het Nederlands Spektator 3 619-646

Chomsky, N 1957 Syntactic structures The Hague Mouton

Chomsky, N 1973 'Conditions on transformations' In S R Anderson and P Kiparsky, eds, A Festschrift for Morris Halle New York Holt, Rinehart and Winston pp 232-286

Chomsky, N 1975 Reflections on language New York Pantheon

Chomsky, N 1976 Conditions on rules of grammar Linguistic Analysis 2 303-351

Chomsky, N 1979 Markedness and core grammar Unpublished (to appear in the Proceedings of the 4 th GLOW colloquium, Pisa)

Cole, $\mathrm{P}$ and J L Morgan, eds 1975 Syntax and semantics, 3 speech acts New York Acddemic Press

Lmonds, J L 1976 A transformationdl approach to English syntax New York Academic Press

Frteschik-Shir, N 1979 On extraction from noun phrases (picture noun phrases) Unpublished (to appear in the Proceedings of the 4 th GLOW colloquium, P1sa)

Grice, H P 1975 'Logic and conversation' In Cole and Morgan, eds pp 41-58

Grice, H P 1978 'I urther notes on logic and conversation' In P Cole, ed, Syntax and seman tics 9 pragmatics New York Academic Press pp 113-127

Gueron, J 1976 'Interpretation of PP complements a semantic filter for PP extraposition' In H C van Riemsdijk, ed, Green ideas blown up Amsterdam University of Amsterdam pp $44-68$

Gueron, J 1979 The grammar of PP extraposition Unpublished, Paris

De Haan, G J 1979 Conditions on rules the proper balance between syntdx and semantics Dordrecht I oris Publications

Jackendoff, R S 1972 Semantic interpretation in gentrative grammar Cambridge, MA The MIT Press

Jdckendoff, R S 1977 X syntax a study of phrase structure Cambridge, MA The MIT Press

Kean, M L 1975 The theory of markedness in generative grammar Unpublished Ph D dissertation, MII (distributed by the IULC I ebruary 1980)

Kempson, R M 1975 Presupposition and the delimitation of semantics Cambridge Cambridge University Press

Keyser, S J 1968 Review of Sven Jdcobson adverbial positions in Lnglish Langudge 44 357373

Koster, J 1978 Locality principles in syntax Dordrecht For1s Publications

Van Riemsdijk, H C 1979 Marking conventions for syntax (talk at the 4th GLOW colloquium, Pisd, April 1979)

Salvcrda, R 1979 'Topıc, focus and preposing in Dutch declarative main clauses' In V d Velde and Vandeweghe, eds pp 133-142

Sedrle, J 1975 'Indrect speech dcts' In Cole and Morgan, eds pp 59-82

V d Velde, M and W Vandeweghe, eds 1979 Sprachstruktur, Individuum und Gesellschaft Tubingen Niemeyer

Verhagen, A 1979a 'Tocus, core grammar and sentence adverbials in Dutch' In Vd Velde and Vandeweghe, eds pp 143-152

Verhagen, A 1979b I okusbepalıngen en grammatıkale theorle Spektator 8 372-402

Verhagen, A $1979 \mathrm{c}$ On contrastive stress Unpublished, I ree Unıversity of Amsterdam

Verhagen, A 1979d On the $I$ hypothesis of dislocation and conditions on discourse grammar Recherches Linguistiqucs 8 131-158 
Arie Verhagen was born on January 18, 1951. He attended the Free University of Amsterdam, where he finished his studies in Dutch Linguistics and Literature in October 1976, with a mas. ter's thesis on the Principle of Expressibility and the relation between sentence meaning and speech acts. From 1976 to 1979 he was appointed to a research project on "Grammar and Pragmatics" (Free University grant 76/4), of which the bulk of the present paper is a result. Since August 1979 he also teaches linguistics at the Dutch department of the Free University. For other publications related to the topic of the present paper, see the bibliography to this paper. 